\title{
QUANTIFYING UNCERTAINTY IN ANALYTICAL MEASUREMENTS
}

\author{
S. B. RASUL, A. MONSUR KAJAL AND A. H. KHAN* \\ Plasma Plus Application \& Research Laboratory, Uttara, Dhaka 1230, Bangladesh
}

\begin{abstract}
In providing chemical, biochemical and agricultural materials testing services for quality specification, the analytical chemists are increasingly required to address the fundamental issues related to the modern concepts of Chemical Metrology such as Method Validation, Traceability and Uncertainty of Measurements. Without this knowledge, the results cannot be recognized as a scientific fact with defined level of acceptability. According to ISO/IEC 17025:2005, this is an essential requirement of all testing laboratories to attain competence to test materials for the desired purpose. Of these three concepts of chemical metrology, the most complex is the calculation of uncertainties from different sources associated with a single measurement and incorporate them into the final result(s) as the expanded uncertainty $\left(\mathrm{U}_{\mathrm{E}}\right)$ with a defined level of reliability (e.g., at 95\% CL). In this paper the concepts and practice of uncertainty calculation in analytical measurements are introduced by using the principles of statistics. The calculation procedure indentifies the primary sources of uncertainties and quantifies their respective contributions to the total uncertainty of the final results. The calculations are performed by using experimental data of Lead (Pb) analysis in soil by GF-AAS and pesticides analysis in wastewater by GC-MS method. The final result of the analytical measurement is expressed as: Result $(\mathbf{m g} / \mathbf{k g})=$ Measured Value of Analyte $(\mathbf{m g} / \mathbf{k g}) \pm$ Uncertainty $(\mathbf{m g} / \mathbf{k g})$, where the uncertainty is the parametric value associated with individual steps in measurements such as sample weighing $\left(\mathbf{U}_{\mathbf{m}}\right)$, extraction of analyte $\left(\mathbf{U}_{\mathbf{e}}\right)\left(\mathrm{Pb}\right.$ from soil or pesticides from water), volumetry in measurement $\left(\mathbf{U}_{\mathbf{v}}\right)$, concentration calibration $\left(\mathbf{U}_{\mathbf{x}}\right)$, etc. The propagation of these individual uncertainties from different sources is expressed as combined relative uncertainty $\left(\mathrm{U}_{\mathrm{c}}\right)$, which is calculated by using the formula:
\end{abstract}

$$
\text { Combined uncertainty }\left(\frac{U_{c}}{c}\right)=\sqrt{\left(\frac{U x}{x}\right)^{2}+\left(\frac{U m}{m}\right)^{2}+\left(\frac{U v}{v}\right)^{2}+\left(\frac{U e}{e}\right)^{2}+\ldots}
$$

The overall uncertainty associated with the final result of the analyte is expressed as Expanded Uncertainty $\left(U_{E}\right)$ at certain level of confidence (e.g. 95\%). The Expanded Uncertainty is calculated by multiplication of Combined Uncertainty $\left(U_{c}\right)$ with a coverage factor $(\mathrm{K})$ according to the proposition of level of confidence. In general, the level of confidence for enormous data is considered at $95 \%, \mathrm{CL}$ where $\mathrm{K}$ is 2 . Hence, the final result of the analyte is expressed as: $\mathrm{X} \pm \mathrm{U}_{\mathrm{E}}$ (unit) at $95 \% \mathrm{CL}$, where $\mathrm{U}_{\mathrm{E}}=2 \mathrm{U}_{\mathrm{c}}$.

\footnotetext{
* Corresponding author: <E-mail: ahk@plasmaplus.org>.
} 
Key words: Measurement uncertainty, atomic absorption spectrophotometry, GC-MS, heavy metals, pesticides, soil, wastewater

\section{INTRODUCTION}

Chemical and biochemical analyses of materials for quality specifications are a continuous need of a modern society. The role of these analyses is very important, for example, in food, drink and air quality analysis for public health assuring, in healthcare services, and in trade and research. In all these cases, what is most important is to get reliable analytical data. And this is achievable when the testing laboratories follow the international standard for assuring the quality of measurement data, namely, ISO/IEC 17025:2005 (General requirements for the competence of testing and calibration laboratories) (Hibbert, B. D., 2007)

This ISO standard has a set of management and technical requirements. The technical requirements of this standard are linked to the science of measurements; meaning that metrological issues such as traceability, uncertainty and validation are the essential components of quality assured analytical data reported with defined levels of uncertainties and defensible confidence limits. The scope of this paper is, however, limited to calculation of uncertainty in analytical measurements that can be uniformly applied to all quantitative chemical analyses.

The uncertainty in a measurement is the interval on the measurement scale within which the true value lies with a specified probability, when all sources of error are taken into account. In modern concepts of chemical metrology, analytical chemists are increasingly required, as a standard practice, to make a statement on the level of uncertainty associated with the estimate of a measurand. Without this knowledge, the measurement cannot be properly interpreted and the acceptability of the test results for a specific purpose cannot be ensured (DOI 10.1039/AN 9952002303, 1995, EUROCHEM/CITAC Guide CG 4, 2012). The measurement of uncertainty in quantitative chemical analysis influences the data generated from each involved in the experimental measurements such as weighing of a sample, extraction of analyte, volumetry of sample solution and calibration of the measuring instrument. The uncertainty measurement in each of these steps thus becomes the most important unifying principle in the overall data quality assessment (GUM, 2008).

This paper briefly introduces the concepts and practices of data quality evaluation in analytical chemistry and outlines the basic procedures of calculating uncertainty in analytical measurement, using the principles of statistics (Harris, C. D., 2010). In the procedure, the primary sources of uncertainty are identified and their respective contributions to the total uncertainty in the final results are calculated for routine measurements, for example, trace metals analysis in different sample matrices. The approach adapted to the calculation of uncertainty in solid and liquid sample matrices is consistent throughout the data quality evaluation process so that it can be uniformly 
applied to all quantitative analyses and thus becomes acceptable to the whole analytical community (Harvey, D., 2000).

\section{Concepts of Error and Uncertainty}

The traditional concept of error in measurements assumes that there is a single true value of a measurand and it can be reached by performing repeated measurements done with care and attention to details. In reality, a measurement procedure defines, to the extent possible, what is measured. On the other hand, uncertainty can only describe a range within which there is a reasonable chance of finding a value that might be attributed to the measurand. A true value can only be defined as the quantity value consistent with the definition of a quantity, which in other words allows the possibility of finding many true values in a range that is defined as the statistical probability of finding the most probable value within the range (Harvey, D., 2000).

\section{Percent Error in Measurements}

Percent error, sometimes referred to as fractional difference, measures the accuracy of a measurement by the difference between a measured or experimental value, $\mathrm{E}$, and a true or accepted value, A. The percent error is calculated from the difference between the two using the following equation:

$$
\% \text { Error }=\frac{E-A}{A}
$$

Types of Errors in Measurements

\section{Type B Uncertainty: Systematic error}

Type B Uncertainty, also known as systematic error or determinate error, arises from the flaw/defect in the equipment used or in the design of the experiment. In this case, if the experiment is repeated under identical conditions, the error would be reproducible. Systematic errors are always in one direction and are of the same magnitude when repeatedly measured. These errors can be found out and corrected by analyzing a CRM for the same parameter. For example, an incorrectly standardized $\mathrm{pH}$ meter with a buffer will produce systematic error. If one uses a buffer with known $\mathrm{pH}$ of 7.00 units to calibrate it, it will give result like 7.08, 0.08 units lower. With this $\mathrm{pH}$ meter if measured a $\mathrm{pH}$ of 5.60 , the actual $\mathrm{pH}$ would be 5.68 units. This error can be found by using another buffer with certified $\mathrm{pH}$ value.

\section{Type A Uncertainty: Random error}

Type A Uncertainty, known as random or indeterminate error, arises from a number of uncontrolled variables such as water quality used in preparation, unstable blank correction, errors in calibration, etc. Random errors cannot be corrected. In repeated 
measurements, random errors have equal chance of being positive and negative. Instrument electronic noise is also a source of random error. If you make $\boldsymbol{n}$ number of measurements, where $\boldsymbol{n}$ is greater than 30 , for example, each data will be different and errors in the measurement will follow a normal distribution like (Kateman, G. and L. Buydens, 1993).

$$
f(x)=\frac{1}{\alpha \sqrt{2 \pi}} \exp \left[\frac{(x-\mu)^{2}}{2 \sigma_{2}}\right]
$$

where $\mu$ is the mean, $\mathrm{x}$ is the individual result, $\sigma$ is the standard deviation, $\pi$ has the usual value. This uncertainty combined with other sources will give the measurement uncertainty with certain degree of probability; say for example, 95\% ( $2 \sigma$ standard deviation), or $99 \%$ ( $3 \sigma$ standard deviation) (Muller, J. C. and J. N. Muller, 1993).

The estimation of measurement uncertainty is a process designed to increase understanding of the measurement result by assessing the factors that influence the measurement. It is also convenient to treat all experimental data statistically to distinguish between random measurement errors, the standard deviation of which can be estimated from repeated measurements, and systematic measurement errors that are oneway deviation which can be measured or estimated and then corrected or included in uncertainty budget. These concepts are explained here in this paper with support of primary measurement data generated in analytical laboratories (ISO/IEC 17025, 2005).

In the traditional Error Approach (or True Value Approach), the objective is to determine an estimate of the true value that is as close as possible to that single true value. The deviation from the true value is composed of random and systematic errors. In the Uncertainty Approach, the objective of measurement is not to determine a true value as closely as possible. Rather, it is assumed that the information from measurement only permits assignment of an interval of reasonable values to the measurand, based on the assumption that no mistake has been made in performing the measurement.

\section{Sources of Uncertainties}

The Steps involved in any analytical measurement are (i) sample preparation (by dissolving a definite weight of a sample in a definite volume), (ii) preparation of standards solutions using CRM, (iii) calibration of measuring equipment and (iv) preparation of sample blank. Each of these steps has some degrees of uncertainties, depending on the level of 'GLP' (good laboratory practice) that has been established in the laboratory. How the contribution from each of these sources to the final uncertainty in the result (combined \& expanded uncertainty) is calculated, is discussed in this paper with examples of $\mathbf{P b}$ analysis in soil and pesticides in wastewater. 


\section{MATERIALS \& METHODS}

Two analytical instrumentations with different sample matrices were considered for this exercise of calculating measurement uncertainty. For this purpose, data were collected from lead $(\mathrm{Pb})$ analysis in soil (as solid sample matrix) by using GF-AAS (Shimadzu, Model: 6800) method and Organophosphorus pesticides analysis in wastewater (as liquid sample matrix) by using GC-MS (Shimadzu, Model: QP 2010) methods. The following laboratory requirements under Good Laboratory Practices (GLP) were taken into consideration for analytical measurements of the selected parameters.

- Validated analytical method and calibrated equipment (Analytical Instrumentations \& Balance) are used.

- Certified Reference Materials (CRMs) are used for equipment calibration

- Appropriate method blanks are prepared for blank correction in each measurement.

- Qualified analysts perform the analysis.

- Availability of Class A Glassware be ensured

- Analar Grade reagents and Reagent grade water with $\mathbf{M} \quad \mathbf{2 1 7}$ were used.

- Clean and safe laboratory environment was ensured.

Data acquisition from $\mathrm{Pb}$ Measurement by GF-AAS

The first exercise of analytical problem considered here for Quantifying Uncertainties is the measurement of Lead $(\mathrm{Pb})$ in a soil sample using Atomic Absorption Spectroscopy (AAS). The following four steps involved in the procedures were considered to be significant sources of uncertainties in this analysis.

(1) $0.5008 \mathrm{~g}$ dried soil sample was weighed using an electronic balance. The uncertainty at standard $500 \mathrm{mg}$ was $\pm 0.25 \mathrm{mg}$ under the repeatability condition of the electronic balance. The standard mass was calibrated from National Metrology Laboratory of Bangladesh Standards and Testing Institution (BSTI).

(2) The soil sample was digested in $\mathrm{HNO}_{3}$ matrix (Analar Grade from $\mathrm{BDH}$ England) and the final volume of digested solution was prepared in a $100 \mathrm{~mL}$ volumetric flask. Uncertainty stated by the manufacturer of Class A glassware for the $100 \mathrm{~mL}$ volumetric flask as $\pm 0.05 \mathrm{~mL}$ (at $20^{\circ} \mathrm{C}$ ). It was considered that the uncertainty regarding dissolution of analyte through digestion procedure is negligible.

(3) Five Lead $(\mathrm{Pb})$ standards were prepared in the concentration range of $\mathbf{0 , 5}, \mathbf{1 0}$, 15 and $20 \mu \mathrm{g} / \mathrm{L}$ (ppb) from certified reference material of Sigma Aldrich. The instrument (AAS) response was measured in absorbance (Abs) against standard 
lead $(\mathrm{Pb})$ solutions and a standard calibration plot was prepared, with triplicate measurements for each standard concentration. The absorbance of digested sample (step-2) was also measured in triplicates with GF-AAS technique and the concentration of Lead $(\mathrm{Pb})$ in the digested solution was calculated from the calibration plot, expressed in $\mu \mathrm{g} / \mathrm{L}$. All the measured data are shown in Table 1.

(4) The repeatability of instrumental response or the precision of the test result was evaluated using quality control standard $(10 \mu \mathrm{g} / \mathrm{L})$ prepared from the CRM. The repeatability data are shown in Table 1.

Table 1: Absorbance of GF-AAS from standard calibration and sample for Pb Measurement

\begin{tabular}{llll}
\hline $\mathrm{Pb}(\mu \mathrm{g} / \mathrm{L})$ & Abs $($ Series -1$)$ & Abs $($ Series -2$)$ & Abs $($ Series - 3) \\
\hline Known $\boldsymbol{x}_{\boldsymbol{i}}$ & $y_{i}(1)$ & $y_{i}(2)$ & $y_{i}(3)$ \\
$\mathbf{0}$ & -0.0004 & 0.0004 & -0.0003 \\
$\mathbf{5}$ & 0.0955 & 0.0956 & 0.0950 \\
$\mathbf{1 0}$ & 0.1786 & 0.1753 & 0.1704 \\
$\mathbf{1 5}$ & 0.2564 & 0.2550 & 0.2531 \\
$\mathbf{2 0}$ & 0.3333 & 0.3292 & 0.3221 \\
\hline$x$ (Digested solution) & $\mathbf{0 . 1 4 2 2}$ & $\mathbf{0 . 1 5 1 2}$ & $\mathbf{0 . 1 4 4 7}$ \\
$\mathbf{C R M ~ 1 0} \mu \mathbf{g} / \mathbf{L}$ & $\mathbf{0 . 1 7 3 3}$ & $\mathbf{0 . 1 7 4 5}$ & $\mathbf{0 . 1 7 1 8}$ \\
\hline
\end{tabular}

The final concentration of $\mathrm{Pb}$ in soil sample was calculated from the actual soil sample taken (from step-1), expressed in $\boldsymbol{\mu g} / \mathbf{k g}$ (ppb). The uncertainties in the final concentration of $\mathrm{Pb}$ in soil have been calculated using the procedures (step 1-4) discussed in the Results and Discussion section.

Data acquisition from Measurement of Organophosphorus Pesticides by GC-MS

The second example considered for quantifying uncertainties is the analysis of Organophosphorus Pesticides (OPP) in wastewater samples using Gas ChromatographyMass Spectrometry (GC-MS). In this excurse a Proficiency Testing (PT) sample from Absolute Standards Inc, USA, containing 15 types of OPP compounds was taken for uncertainty calculation. For concentration calibration of the GC-MS method, a certified reference material (CRM), also from Absolute Standards, having the certified concentration of $1000 \mu \mathrm{g} / \mathrm{L}$ was used.

The original PT sample of $1 \mathrm{~mL}$, provided in an ampoule, was diluted to $1000 \mathrm{~mL}$ as per the sample preparation guide. The finally evaluated PT results where each analyte was assigned a value from interlaboratory comparison study were used for uncertainty calculation. The typical GC-MS chromatogram for standard OPP is shown in the Figure 1. The uncertainty calculation procedures are discussed in the Results and Discussion section. 
The uncertainty of test results was calculated for two OPP compounds, Parathion Methyl and Malathion out of 15 compounds of OPP in the sample as a model calculation. The sources of uncertainties in the analytical procedure were assumed to be each of the following steps involved in the analytical procedure.

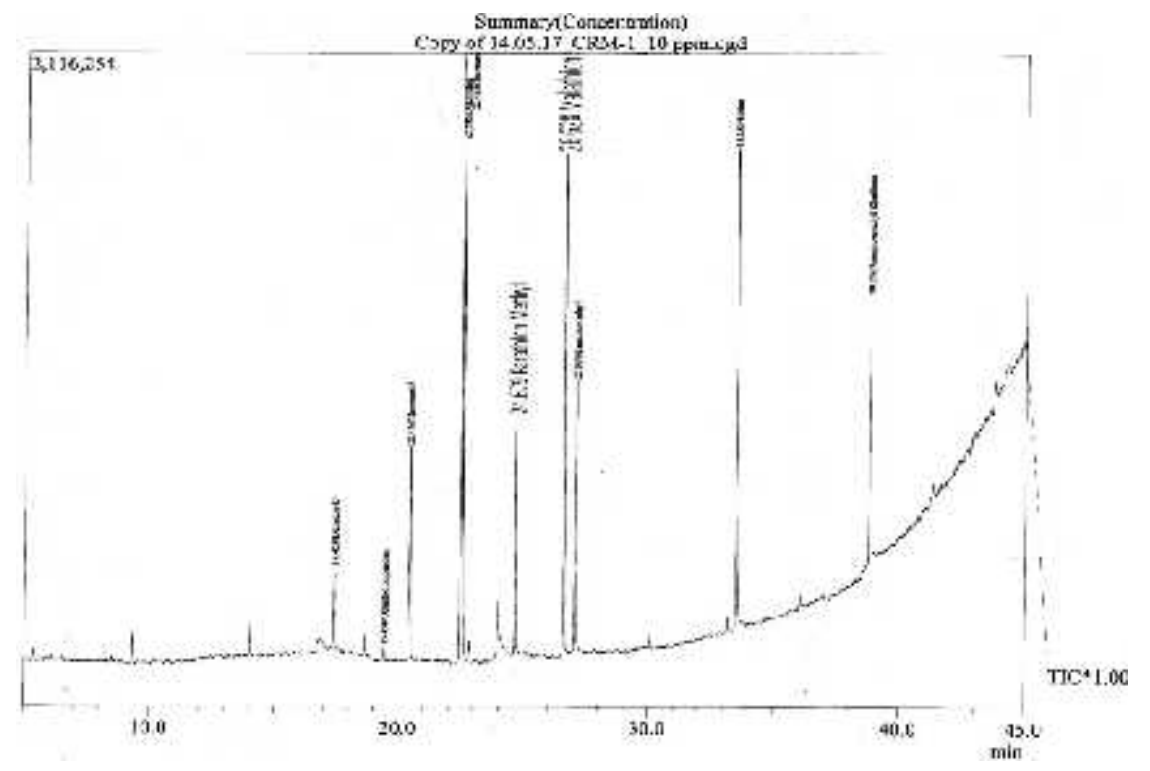

Fig. 1. GC-MS chromatogram of Organophosphorus pesticides (OPP) certified reference material (CRM)

(1) $1 \mathrm{~mL}$ supplied sample was pipetted out from the ampoule and diluted to 1000 $\mathrm{mL}$ in a volumetric flask, using Reagent Grade water $(\mathbf{M} \geq \mathbf{1 7})$. The uncertainties from volumetry were $\pm 0.01 \mathrm{~mL}$ for $1 \mathrm{~mL}$ sample and $\pm 0.5 \mathrm{~mL}$ for $1000 \mathrm{~mL}$ sample.

(2) The pesticides in diluted sample were extracted in organic solvent (Hexane, HPLC Grade by RCI Labscan Ltd, Thailand) and recovered through evaporation of solvent in a rotary evaporator. The extraction efficiency of such solvent extraction procedure is generally considered to be $85 \%$.

(3) The final volume of the sample was constituted to $1 \mathrm{~mL}$ solvent (mixture of Acetone \& Hexane) for injecting into the GC column for separation of different components. The injection volume was $2 \mu \mathrm{L}$ for each calibration standard, sample and QC standard.

(4) Standard calibrations were carried out for each compound of OPP using the GCMS instrumentation, where mean peak areas were recorded against standard concentration by the application software of the analytical instrument. Table 2 shows the calibration data for the two compounds of OPP, used for quantifying measurement uncertainty. 
Table 2: Mean Peak area from GC-MS Chromatogram against standard Parathion Methyl \& Malathion

\begin{tabular}{cccc}
\hline Parathion Methyl $(\mu \mathrm{g} / \mathrm{mL})$ & Peak Area (Mean) & Malathion $(\mu \mathrm{g} / \mathrm{mL})$ & Peak Area $($ Mean $)$ \\
\hline Known $x_{i}$ & $y_{i}$ & Known $x_{i}$ & $y_{i}$ \\
2.5 & 9915 & 2.5 & 13693 \\
5 & 25274 & 5 & 36701 \\
10 & 46199 & 10 & 62757 \\
20 & 147461 & 20 & 200099 \\
40 & 292304 & 40 & 360278 \\
\hline
\end{tabular}

(5) The peak area of individual compound of OPP in PT sample was also recorded repeatedly 5 times by the instrument. In addition, 10 ppm QC standard of each compound was also used to see the run to run variation and recovery factor. Table 3 shows the peak areas of two compounds of PT sample and the QC standard. Though the application software showed the concentration of each OPP compounds of PT sample and QC standard, the concentration of two compounds have been calculated here using Least Squares Method for the exercise of Measurement Uncertainty.

Table 3: Peak area from GC-MS Chromatogram against unknown Parathion Methyl \& Malathion in PT sample

\begin{tabular}{|c|c|c|c|c|}
\hline \multicolumn{3}{|c|}{ Parathion Methyl (Peak Area from GC-MS) } & \multicolumn{2}{|c|}{ Malathion (Peak Area from GC-MS) } \\
\hline & $\begin{array}{l}\text { PT Sample } \\
\text { (extract) }\end{array}$ & $\begin{array}{l}\text { QC Standard } \\
(10 \mathrm{ppm})\end{array}$ & $\begin{array}{l}\text { PT Sample } \\
\text { (extract) }\end{array}$ & $\begin{array}{l}\text { QC Standard } \\
(10 \mathrm{ppm})\end{array}$ \\
\hline & 97185 & 461992 & 117263 & 62757 \\
\hline & 105872 & 437634 & 122193 & 64229 \\
\hline & 121314 & 402111 & 135730 & 57163 \\
\hline & 135771 & 433077 & 141302 & 56387 \\
\hline & 135170 & 418537 & 152160 & 60830 \\
\hline & & 439061 & & 60653 \\
\hline & & 455907 & & 57278 \\
\hline & & 439784 & & \\
\hline Count(n) & 5 & 8 & 5 & 7 \\
\hline Mean & 119062 & 436013 & 133729 & 59899 \\
\hline SD & 17294 & 19124 & 14188.6 & 3028.8 \\
\hline$\%$ RSD & $14.5 \%$ & $4.4 \%$ & $10.6 \%$ & $5.1 \%$ \\
\hline
\end{tabular}

\section{Computation of Measurement Uncertainty}

The statistical method for linear least squares fit in concentration calibration is applied for the calculation of uncertainty from the standard calibration that is considered 
as one of the major sources of uncertainty in the analytical procedure. The statistical equations for linear calibration plot are described in the reference books (Harris, C. D., 2010, Kateman, G. and L. Buydens). These equations are used in this exercise to explain the process involved in measurement uncertainty. Simple tabular format for data acquisition and a scientific calculator can be used for this exercise, as shown in the uncertainty calculation procedure for $\mathrm{Pb}$ analysis in soil. Alternatively, personal computer based MS Excel spreadsheet application software can also be used for data acquisition and necessary calculation of measurement uncertainty, as used here for pesticides analysis in wastewater.

\section{RESULTS AND DISCUSSION}

Process steps of measurement uncertainty for Lead $(\mathrm{Pb})$ in soil sample

1. Construction of linear calibration plot using Least Squares Method (LSM) and measure unknown concentration

Table 1 shows that three absorbance values (replicate) were measured against each standard concentration of Lead $(\mathbf{P b})$. The calculation procedures of uncertainties associated with lead concentration measurement in a soil sample are described below.

In this regard, the 'Least Squares Equation' (3) is the appropriate one for constructing the calibration curve.

$$
y=m x+b
$$

where,

$y=$ Abs (instrument response against $\mathbf{m} \boldsymbol{\&} \mathbf{b}$ values are calculated using the standard analyte) following least-squares equations:

$$
\begin{aligned}
& \begin{array}{l}
x=\text { concentration }(\mu \mathrm{g} / \mathrm{L}, \text { standard analyte }) \quad m=\frac{n \sum\left(x_{i} y_{i}\right)-\sum x_{i} \sum y_{i}}{n \sum\left(x_{i}^{2}\right)-\left(\sum x_{i}\right)^{2}} \\
m=\text { slope of linear equation }
\end{array} \\
& b=\text { intercept on y axis of liner equation } \quad b=\frac{\sum\left(x_{i}^{2}\right) \sum y_{i}-\sum\left(x_{i} y_{i}\right) \sum x_{i}}{\left.n \sum x_{i}^{2}\right)-\left(\sum x_{i}\right)^{2}} \\
& x_{i}=\text { individual value of standard analyte } \\
& y_{i}=\text { individual value of absorbance against } \\
& \text { each standard analyte }
\end{aligned}
$$

The computation of $\boldsymbol{m} \boldsymbol{\&} \boldsymbol{b}$ values using experimental data $\left(\boldsymbol{x}_{i} \& y_{t}\right)$ is shown in Table 4. Accordingly, the calculated values of $m \& b$ are found to be $0.016 \& 0.007$ respectively. 
Table 4: Variables for calculating slope (m) and $y$-intercept $(b)$

\begin{tabular}{|c|c|c|c|c|c|}
\hline \multirow[t]{2}{*}{ Series } & $\mathrm{Pb}(\mu \mathrm{g} / \mathrm{L})$ & Abs & \multirow{2}{*}{$x_{i}^{2}$} & \multirow{2}{*}{$x_{i} y_{i}$} & \multirow{2}{*}{$\begin{array}{l}\text { Calculation of } \mathrm{m} \& \text { b value from } \\
\text { Eq. } 4 \& 5\end{array}$} \\
\hline & $x_{i}$ & $y_{i}$ & & & \\
\hline \multirow{5}{*}{ 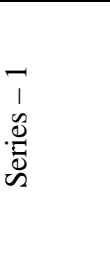 } & 0 & -0.0004 & 0 & 0 & \multirow{5}{*}{$\begin{array}{l}\text { The number of data set } n \text { is } 15 \text { ( } 5 \text { data } \\
\text { sets from each series) }\end{array}$} \\
\hline & 5 & 0.0955 & 25 & 0.4775 & \\
\hline & 10 & 0.1786 & 100 & 1.786 & \\
\hline & 15 & 0.2564 & 225 & 3.846 & \\
\hline & 20 & 0.3333 & 400 & 6.666 & \\
\hline \multirow{5}{*}{$\begin{array}{l}1 \\
1 \\
0 \\
0 \\
0 \\
0 \\
0\end{array}$} & 0 & 0.0004 & 0 & 0 & \multirow{10}{*}{$\begin{array}{l}b=\frac{2250 \times 2.599-37.833 \times 150}{15 \times 2250-22500} \\
b=0.0074\end{array}$} \\
\hline & 5 & 0.0956 & 25 & 0.478 & \\
\hline & 10 & 0.1753 & 100 & 1.753 & \\
\hline & 15 & 0.255 & 225 & 3.825 & \\
\hline & 20 & 0.3292 & 400 & 6.584 & \\
\hline \multirow{5}{*}{$\begin{array}{l}m \\
1 \\
0 \\
0 \\
0 \\
0 \\
\infty\end{array}$} & 0 & -0.0003 & 0 & 0 & \\
\hline & 5 & 0.095 & 25 & 0.475 & \\
\hline & 10 & 0.1704 & 100 & 1.704 & \\
\hline & 15 & 0.2531 & 225 & 3.7965 & \\
\hline & 20 & 0.3221 & 400 & 6.442 & \\
\hline
\end{tabular}

The standard calibration curve is shown in Figure 2. This linear regression line is constructed using the data shown in Table 4. The concentration ( $x$ value) of unknown sample is calculated using this calibration plot, based on the linear Equation (3). Table 5 shows the measured absorbance ( $y$ value) of unknown analyte and the calculation of concentration of $\mathrm{Pb}(x$ value $)$ in the digested solution and the soil sample.

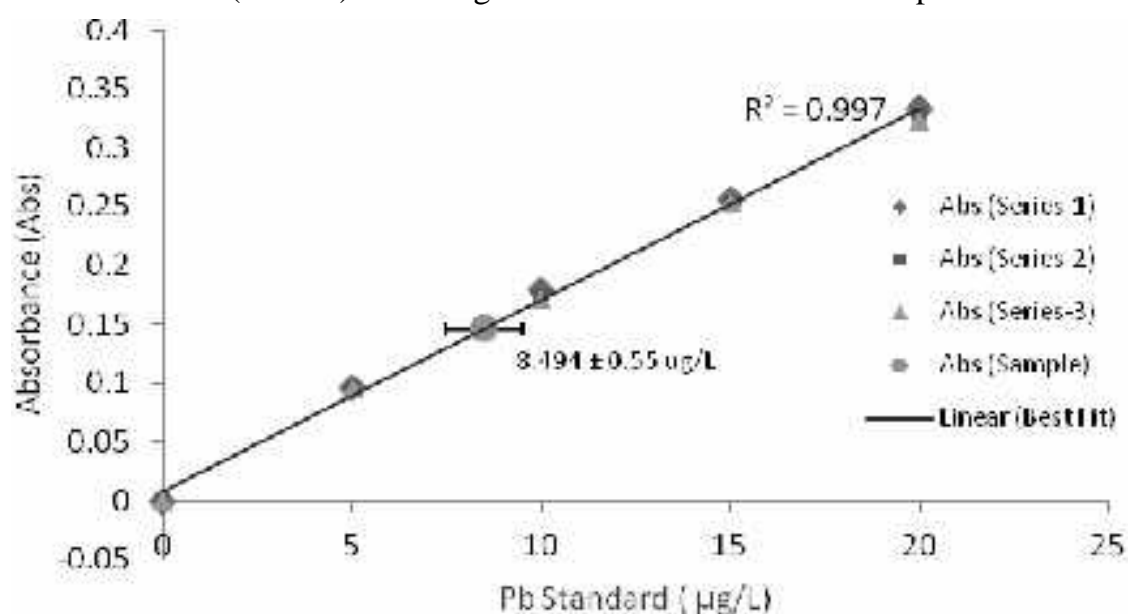

Fig. 2. Calibration plot of Standard Lead concentration versus Absorbance using GF-AAS; sample concentration $(\mathrm{x}=8.494 \mu \mathrm{g} / \mathrm{mL})$ is measured with uncertainty $\left(U_{\mathrm{x}}=0.55 \mu \mathrm{g} / \mathrm{mL}\right)$ using LSM, is shown by circle dot with error bar. 
Table 5: Calculation of unknown analyte concentration in digested solution and soil sample

\begin{tabular}{ccccc}
\hline $\begin{array}{c}\text { Abs } \\
\text { (replicate })\end{array}$ & $\begin{array}{c}\text { Average } \\
(\mathrm{Abs})\end{array}$ & $\begin{array}{c}\mathrm{Pb}(\mu \mathrm{g} / \mathrm{L}) \text { in digested } \\
\text { solution }\end{array}$ & $\mathrm{Pb}(\mu \mathrm{g} / \mathrm{g})$ in soil sample \\
\hline$y_{j}$ & $y$ & \multicolumn{2}{c}{$\mathrm{x}=(\mathrm{y}-\mathrm{b}) / \mathrm{m}$} & \\
0.1422 & & 8.26 & $\mu \mathrm{gPb} / \mathrm{g}$ soil $(\mathrm{c})=\frac{\mathrm{Pb}(\mathrm{g})}{\text { sample taken }(\mathrm{g})} \times \frac{1}{10}$ \\
0.1512 & & 8.81 & $8.494 \pm 0.285$ & $=\frac{8.494}{0.5008} \times \frac{1}{10}$ \\
0.1447 & & 8.1460 & & $=1.696$ \\
\hline
\end{tabular}

Table 6: Calculation of QC standard (CRM) concentration, repeatability \& recovery

\begin{tabular}{|c|c|c|c|c|}
\hline $\begin{array}{c}\text { Abs } \\
\text { (replicate) }\end{array}$ & $\begin{array}{c}\text { Average } \\
\text { (Abs) }\end{array}$ & $\begin{array}{r}\text { Calculated } \\
\mathbf{P}\end{array}$ & $\begin{array}{l}\text { of QC Std. of } \\
\text { /L) }\end{array}$ & Interpretation \\
\hline 0.1733 & \multirow{3}{*}{0.1732} & 10.16 & \multirow{3}{*}{$10.16 \pm 0.083$} & \multirow{3}{*}{ Standard Recovery $=101.6 \%$} \\
\hline 0.1745 & & 10.24 & & \\
\hline 0.1718 & & 10.07 & & \\
\hline
\end{tabular}

2. Uncertainty in unknown analyte ( $x$ ) from Calibration Plot

Since the calculation of an $x_{i}$ th-value from a given $y_{i}$ th-value involves the use of both the slope $(\mathrm{m})$ and intercept $(b)$, all these values are subject to error. So, the error is expressed as Uncertainty in $x\left(\mathrm{~s}_{\mathrm{x}}\right)$ which is calculated from the Least Squares Method following the equations below ${ }^{4,7}$ :

Uncertainty in $x\left(\mathrm{~s}_{\mathrm{x}}\right)=\frac{s_{y}}{|m|} \sqrt{\frac{1}{k}+\frac{1}{n}+\frac{(y-Y)^{2}}{m^{2} \sum\left(x_{i}-X\right)^{2}}}$

where,

$s_{y}=$ standard deviation of $y_{i}$ th values (Eq. 5) from the calibration curve

$=\sqrt{\frac{\sum(d)_{i}^{2}}{n-2}}$

where, $d_{i}=$ the vertical deviation for the point $\left(\mathrm{x}_{\mathrm{i}}, \mathrm{y}_{\mathrm{i}}\right)$ in the calibration line

$$
=y_{i}-\dot{y}=y_{i}-\left(m x_{i}+b\right)
$$

where, $\dot{y}$ is the ordinate of the straight line when $\dot{x}=x_{i}$ $n-2=$ degrees of freedom $(\delta)$

and in Equation (6):

$|m| \quad=$ absolute value of the slope

$k \quad=$ number of replicate absorbance (y) measurement of the unknown

$n \quad=$ the number of data points on the calibration line 
$y \quad=$ mean value of absorbance of unknown sample

$\bar{Y} \quad=$ mean value of for the points on the calibration line

$x_{i} \quad=$ individual values of $x$ for the points on the calibration line

$\bar{X} \quad=$ mean value of $x$ for the points on the calibration line

Accordingly, using Equations (6 \& 7), standard deviation in $y_{i}$ th values and uncertainty in concentration of $\mathrm{Pb}$ in soil digest, $x$, was calculated and the results are computed in Table 7 \& Table 8:

Table 7: Computation of standard deviation of $y_{i}$ th values ( $s_{y}$ value from equation 7)

\begin{tabular}{|c|c|c|c|c|c|c|}
\hline & $\mathrm{Pb}(\mu \mathrm{g} / \mathrm{L})$ & Abs & \multirow{2}{*}{$d_{i}$} & \multirow{2}{*}{$d_{i}^{2}$} & \multirow{2}{*}{$\left(x_{i}-\bar{X}\right)^{2}$} & \multirow{2}{*}{ Calculation of $s_{y}$} \\
\hline & $x_{i}$ & $y_{i}$ & & & & \\
\hline \multirow{5}{*}{$\begin{array}{l}1 \\
1 \\
0 \\
0 \\
0 \\
0 \\
\infty\end{array}$} & 0 & -0.0004 & -0.0078 & $6.084 \mathrm{E}-05$ & 100 & \multirow{5}{*}{$\begin{array}{l}d_{i}=y_{i}-\left(m x_{i}+b\right), \\
\text { where values of } m \text { and } b \\
\text { were obtained from Table } \\
\text { 4. } \\
\sum\left(x_{i}-\bar{X}\right)^{2}=750\end{array}$} \\
\hline & 5 & 0.0955 & 0.0064 & $4.2163 \mathrm{E}-05$ & 25 & \\
\hline & 10 & 0.1786 & 0.0079 & $6.3787 \mathrm{E}-05$ & 0 & \\
\hline & 15 & 0.2564 & 0.0041 & $1.7472 \mathrm{E}-05$ & 25 & \\
\hline & 20 & 0.3333 & -0.0005 & $2.7738 \mathrm{E}-07$ & 100 & \\
\hline \multirow{5}{*}{ 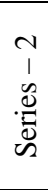 } & 0 & 0.0004 & -0.007 & $4.9 \mathrm{E}-05$ & 100 & \multirow{5}{*}{$\begin{array}{l}\sum d_{i}^{2}=0.00056 \\
s y=\sqrt{\frac{\sum\left((d)_{i}^{2}\right)}{n-2}}\end{array}$} \\
\hline & 5 & 0.0956 & 0.0065 & 4.3472E-05 & 25 & \\
\hline & 10 & 0.1753 & 0.0046 & $2.1965 \mathrm{E}-05$ & 0 & \\
\hline & 15 & 0.255 & 0.0027 & 7.7284E-06 & 25 & \\
\hline & 20 & 0.3292 & -0.0046 & $2.1406 \mathrm{E}-05$ & 100 & \\
\hline \multirow{5}{*}{$\begin{array}{l}n \\
1 \\
0 \\
0 \\
0 \\
0 \\
0 \\
n\end{array}$} & 0 & -0.0003 & -0.0077 & $5.929 \mathrm{E}-05$ & 100 & \multirow{5}{*}{$\begin{array}{l}s y=\sqrt{\frac{0.00050}{15-2}} \\
=0.006573\end{array}$} \\
\hline & 5 & 0.095 & 0.0059 & $3.592 \mathrm{E}-05$ & 25 & \\
\hline & 10 & 0.1704 & -0.0002 & 4.5511E-08 & 0 & \\
\hline & 15 & 0.2531 & 0.0008 & 7.744E-07 & 25 & \\
\hline & 20 & 0.3221 & -0.0117 & 0.00013751 & 100 & \\
\hline
\end{tabular}

Table 8: Computation of uncertainty $\left(\mathrm{S}_{\mathrm{x}}\right)$ in $x$ value $(\mathrm{Pb}$ in digested sample) from equation 6

\begin{tabular}{|c|c|c|}
\hline Parameters & $\begin{array}{l}\text { Calculated } \\
\text { Value }\end{array}$ & $\begin{array}{l}\text { Uncertainty in } \mathrm{x}\left(\mathrm{U}_{\mathrm{x}}\right) \text { in unknown } \\
\text { analyze })\end{array}$ \\
\hline n (number of data set, Table 7) & 15 & \multirow{10}{*}{$\begin{array}{l}S x=\frac{S_{y}}{|m|} \sqrt{\frac{1}{k}+\frac{1}{n}+\frac{(y-Y)^{2}}{m^{2} \sum\left(x_{i}-\bar{X}\right)}} \\
S x=\frac{0.006573}{\mid 0.0163} \sqrt{\frac{1}{3}+\frac{1}{15}+\frac{6.69 E-06}{0.1998}} \\
S_{x}=0.2547 \\
U_{x}= \pm t S_{x}=(2.160)(0.2547) \\
U_{x}= \pm 0.552\end{array}$} \\
\hline $\mathrm{k}$ (number of data of $\mathrm{y}_{\mathrm{j}}$ th value, Table 5) & 3 & \\
\hline $\bar{Y}$ (Table-4) (mean value of $\mathrm{y}_{\mathrm{i}}$ th, Table 7) & 0.171 & \\
\hline$y\left(\right.$ mean value of $y_{j}$ th, Table 5) & 0.1460 & \\
\hline$(y-\bar{Y})^{2}$ & 0.000604 & \\
\hline $\bar{X}\left(\right.$ mean value of $x_{i},(150 \div 15)$, Table 7$)$ & 10 & \\
\hline$\sum\left(x_{i}-\bar{X}\right)^{2} \Sigma($ Table 7$)$ & 750 & \\
\hline$m^{2} \sum\left(x_{i}-\bar{X}\right)^{2}\left(0.0163^{2}\right.$ X 750) & 0.1998 & \\
\hline$s_{\mathrm{y}}($ from Table 7$)$ & 0.006573 & \\
\hline $\pm t\left(\right.$ from $t$-Table, Statistical Reference $\left.{ }^{4,7}\right)$ & $\begin{array}{l}2.16 \text { at } \\
95 \% \mathrm{CI}\end{array}$ & \\
\hline
\end{tabular}


3. Standard uncertainty budget in total analytical process for Pb in soil using GF-AAS Technique

The Uncertainty in the concentration $\left(\mathbf{U}_{\mathbf{c}}\right)$ of Lead $(\mathrm{Pb})$ in soil sample is the combination of the standard uncertainties from the following sources, summarized in Table 9:

Table 9: Standard uncertainty from different steps of analysis

\begin{tabular}{|c|c|c|c|c|}
\hline \multicolumn{2}{|c|}{ Sources of standard uncertainty } & \multirow{2}{*}{$\begin{array}{l}\text { Value }(f) \\
8.494 \\
\mu \mathrm{g} / \mathrm{L}\end{array}$} & \multirow{2}{*}{$\begin{array}{c}\text { Standard } \\
\text { Uncertainty } \mathrm{u}(f) \\
0.552 \mu \mathrm{g} / \mathrm{L}\end{array}$} & Justification \\
\hline$x$ & Standard calibration plot & & & $\begin{array}{l}\mathrm{U}_{\mathrm{x}}= \pm \mathrm{tS}_{\mathrm{x}}=0.552 \text { from } \\
\text { Table-8 }\end{array}$ \\
\hline$p$ & $\begin{array}{l}\text { Repeatability of sample } \\
\text { conc. Due to matrix effect }\end{array}$ & $\begin{array}{l}8.494 \\
\mu \mathrm{g} / \mathrm{L}\end{array}$ & $\begin{array}{l}3.35 / \sqrt{ } 3=1.93 \% \\
=0.0193 \text { as } \mathrm{RSD}\end{array}$ & $\begin{array}{l}\mathrm{RSD}=3.35 \% \text { obtained } \\
\text { from repeated measurement } \\
(\mathrm{n}=3)\end{array}$ \\
\hline$r$ & $\begin{array}{l}\text { Recovery of standard } \\
\text { concentration }\end{array}$ & $10 \mu \mathrm{g} / \mathrm{L}$ & $0.083 / \sqrt{3}=0.048$ & $\begin{array}{l}\mathrm{SD}=0.083 \quad(\mathrm{n}=3), \text { from } \\
\text { replicate experiments }\end{array}$ \\
\hline$v$ & $\begin{array}{l}\text { Volume of flask used for } \\
\text { adjustment of final } \\
\text { digested solution }\end{array}$ & $100 \mathrm{~mL}$ & $\begin{array}{l}0.05 / \sqrt{ } 3=0.0288 \\
\mathrm{~mL}\end{array}$ & $\mathrm{U}_{\mathrm{v}}=\frac{0.05 m l}{\sqrt{3}}$ \\
\hline & & & & $\pm 0.05 \mathrm{~mL}^{*}$ \\
\hline$m$ & $\begin{array}{l}\text { Mass of soil sample taken } \\
\text { for sample preparation }\end{array}$ & $0.5008 \mathrm{~g}$ & $\begin{array}{l}0.00025 / 1.97= \\
0.00013 \mathrm{~g}\end{array}$ & $\mathrm{U}_{\mathrm{m}}=\frac{0.00025 \mathrm{~g}}{1.97} * *$ \\
\hline
\end{tabular}

* Standard uncertainty in volume, assuming rectangular distribution due to temperature variation

** Standard uncertainty mass in assuming $95 \%$ confidence level

Figure 3 shows the contribution of standard uncertainty from different steps of analytical process and it is pertinent that the contribution of uncertainty from calibration is pre-dominant.

\section{Propagation of uncertainty and Expanded uncertainty}

The propagation of uncertainties in the final concentration of lead in soil sample contributed from different sources is defined as Combined Uncertainty $\left(U_{c}\right)$, which is calculated by using the formula:

$$
\begin{aligned}
\frac{U_{c}}{(c)}=\sqrt{\left(\frac{U x}{x}\right)^{2}+\left(\frac{U p}{x}\right)^{2}+\left(\frac{U r}{s}\right)^{2}+\left(\frac{U m}{m}\right)^{2}+\left(\frac{U v}{v}\right)^{2}} \\
\frac{U_{c}}{(1.696)}=\sqrt{\left(\frac{0.552}{8.494}\right)^{2}+\left(\frac{0.0193}{8.494}\right)^{2}+\left(\frac{0.048}{10}\right)^{2}+\left(\frac{0.00013}{0.508}\right)^{2}+\left(\frac{0.0288}{100}\right)^{2}} \text { (from Table-9) } \\
=\sqrt{0.0043} \\
U c=1.696 \sqrt{0.00043}=0.1106
\end{aligned}
$$




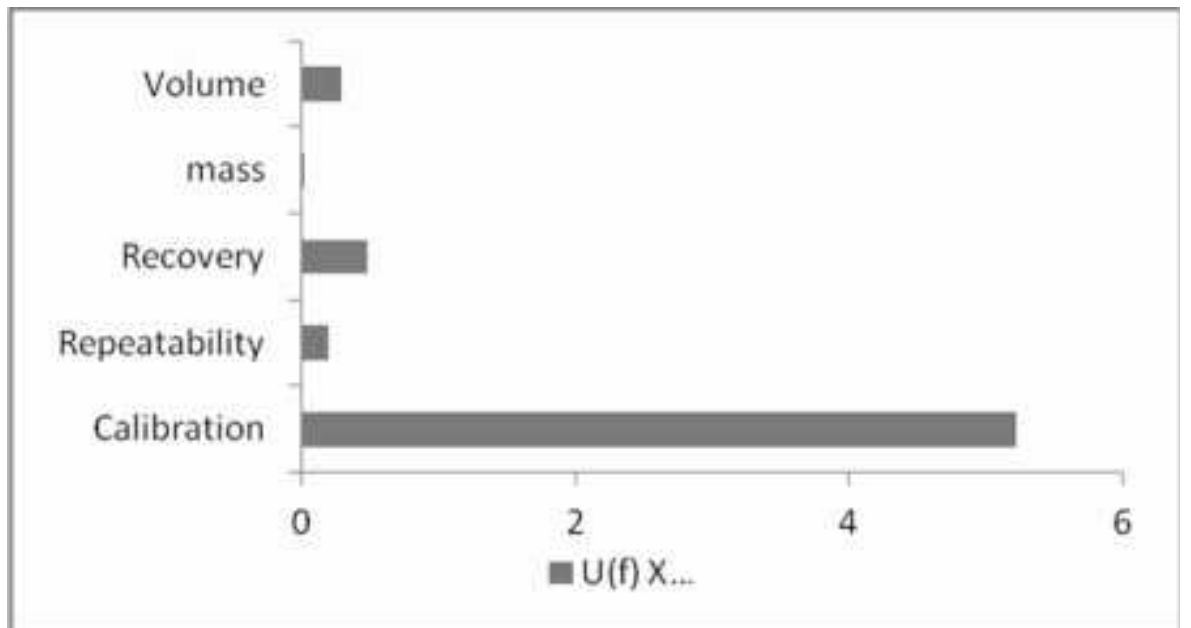

Fig. 3. Contribution of standard uncertainty from different sources (Table-9); Uncertainty from calibration is predominant

\section{Expanded Uncertainty $\left(\mathbf{U}_{E}\right)$}

The Expanded Uncertainty is expressed as multiplication of combined uncertainty with a coverage factor based on desired confidence interval (CI). Generally, the coverage factor $(K)$ is considered 2 for $95 \%$ confidence level. So, Expanded uncertainty $\left(\mathrm{U}_{\mathrm{E}}\right)$ for $\mathrm{Pb}$ in soil is $2 \times U_{\mathrm{c}}=2 \times 0.1046=0.2092 \mu \mathrm{g} / \mathrm{g}$ soil

\section{Lead $(\mathrm{Pb})$ concentration in soil with expanded uncertainty}

The final result of $\mathrm{Pb}$ analysis in Soil is expressed as: $\mathbf{X} \pm \mathbf{U}_{\mathbf{E}}$ (unit) at $\mathbf{9 5 \%}$ confidence level. In the given example, the final result is $1.696 \pm 0.21 \mu \mathrm{g} \mathrm{Pb} / \mathrm{g}$ soil (at 95\% CL). So, the final value, if expressed as $\mathrm{mg} / \mathrm{kg}$, would be: $1.69 \pm \mathbf{0 . 2 1} \mathbf{~ m g ~ P b / k g}$ soil (at $95 \%$ confidence limit).

Process steps of measurement uncertainty for Pesticide in wastewater

6. Construction of linear calibration plot using LSM (value of $m \& v$ ) and measured unknown concentration

Table 10 shows the Excel spreadsheet for computing linear calibration for Parathion Methyl pesticide as an example based on the data shown in Table 2. Table 10 shows the Excel command formula $f(x)$ next to the cell of each calculated value for each variable of LSM method. The symbols of all parameters of Least Squares Equation are the same as was discussed in the first exercise. 
Table 10: Excel Spreadsheet for calculation of the variable of LSM ( $m \&$ b value) \& measurement uncertainty $\left(\mathbf{U}_{\mathrm{x}}\right)$

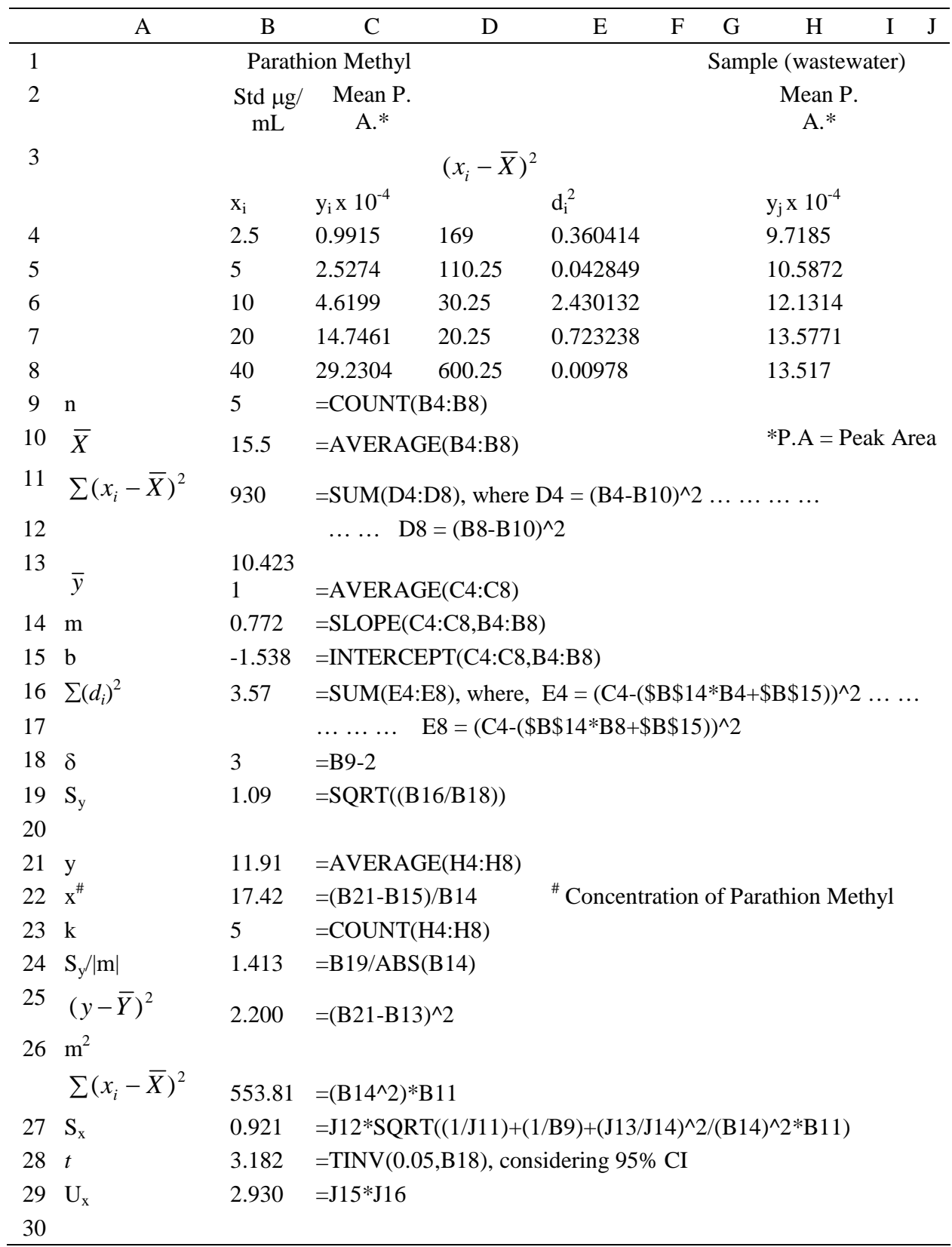

The concentration of Parathion Methyl in the PT sample is shown in Table 11 based on the data of Table 3 and that of Excel spreadsheet of Table 10. The concentration of Malathion is also shown in Table 11 based on the data of Table 3 and that of spreadsheet calculation following Table 10. 
Table: 11: Parameters of calibration plot and the concentration of two pesticides (model calculation)

\begin{tabular}{lccccc}
\hline PT Sample & $\begin{array}{c}\text { Slope } \\
(\mathrm{m})\end{array}$ & $\begin{array}{c}\text { Intercept } \\
(\mathrm{b})\end{array}$ & $\begin{array}{c}\text { Concentration } \\
(x) \text { in } 1 \mathrm{ml} \\
\text { extract }(\mu \mathrm{g} / \mathrm{mL})\end{array}$ & $\begin{array}{c}\text { Conc }(x) \text { in diluted }(1000 \\
\mathrm{mL}) \text { wastewater }(\mu \mathrm{g} / \mathrm{L})\end{array}$ & $\begin{array}{c}\text { Uncertainty } \\
\left(\mathrm{U}_{\mathrm{x}}\right)\end{array}$ \\
\hline $\begin{array}{l}\text { Parathion } \\
\text { Methyl }\end{array}$ & 0.7717 & -1.538 & 17.422 & $17.422(\mathrm{RSD}=9.93 \%, \mathrm{n}=5)$ & \pm 2.930 \\
$\begin{array}{l}\text { Malathion } \\
0.9483\end{array}$ & -1.227 & 15.397 & $15.397(\mathrm{RSD}=9.72 \%, \mathrm{n}=5)$ & \pm 3.799 \\
\hline
\end{tabular}

\section{Uncertainty in unknown analyte $(x)$ and QC standard from Calibration Plot}

In Table 10, the uncertainty of concentration $\left(U_{\mathrm{x}}\right)$ of Parathion Methyl, computed equation 6, is \pm 2.930 and for Malathion, it is \pm 3.799. In Table 12, repeatability in concentration and the recovery of the CRM standard $(10 \mathrm{ppm})$ is computed. It is noted that, the percent recovery of the standard is about $25 \%$ lower than the certified value. The uncertainties for CRM of both pesticides are calculated from the repeatability of the standard.

Table 12: Recovery and repeatability of CRM - QC standard (10 ppm each)

\begin{tabular}{lcccc}
\hline & $\begin{array}{c}\text { Recovery } \\
\text { from standard }\end{array}$ & $\begin{array}{c}\text { Standard } \\
\text { deviation }\end{array}$ & $\begin{array}{c}\text { Number of } \\
\text { data points }\end{array}$ & Uncertainty \\
\hline Parathion Methyl $(10 \mathrm{ppm})$ & $7.64(76.4 \%)$ & 0.25 & 8 & $0.25 / \sqrt{ } 8= \pm 0.088$ \\
Malathion $(10 \mathrm{ppm})$ & $7.46(74.6 \%)$ & 0.22 & 7 & $0.22 / \sqrt{ } 7= \pm 0.083$ \\
\hline
\end{tabular}

8. Standard uncertainty budget in total analytical process for Pesticide analysis in wastewater

In Table 13, the contributions of standard uncertainties from different sources are computed for both pesticides.

Table 13: Standard uncertainty from different analytical steps

\begin{tabular}{|c|c|c|c|c|c|}
\hline & & \multicolumn{2}{|c|}{ Parathion Methyl } & \multicolumn{2}{|r|}{ Malathion } \\
\hline & $\begin{array}{c}\text { Sources of standard } \\
\text { uncertainty }\end{array}$ & Value $(f)$ & $\begin{array}{c}\text { Standard } \\
\text { Uncertainty } \mathrm{u}(f)\end{array}$ & Value $(f)$ & $\begin{array}{c}\text { Standard } \\
\text { Uncertainty } \mathrm{u}(f)\end{array}$ \\
\hline$x$ & $\begin{array}{l}\text { Standard calibration } \\
\text { plot }\end{array}$ & $\begin{array}{l}17.422 \\
\text { ppm }\end{array}$ & $2.930 \mathrm{ppm}$ & $\begin{array}{l}15.397 \\
\text { ppm }\end{array}$ & $3.799 \mathrm{ppm}$ \\
\hline$p$ & $\begin{array}{l}\text { Repeatability of sample } \\
\text { conc. due to matrix } \\
\text { effect }\end{array}$ & $\begin{array}{l}17.422 \\
\mathrm{ppm}\end{array}$ & $\begin{array}{l}9.93 \% / \sqrt{ } 5=4.44 \% \\
=0.0441\end{array}$ & 15.397 & $\begin{array}{l}9.72 \% / \sqrt{ } 5=4.35 \% \\
=0.0435\end{array}$ \\
\hline$r$ & $\begin{array}{l}\text { Recovery of standard } \\
\text { concentration (CRM) }\end{array}$ & $10 \mathrm{ppm}$ & $0.088 \mathrm{ppm}$ & $10 \mathrm{ppm}$ & $0.083 \mathrm{ppm}$ \\
\hline$V 1$ & $\begin{array}{l}\text { Volume of Pipette for } \\
\text { dispensing sample } \\
\text { from the ampoule* }\end{array}$ & $1 \mathrm{~mL}$ & $0.01 / \sqrt{3}=0.0058$ & $1 \mathrm{~mL}$ & $0.01 / \sqrt{3}=0.0058$ \\
\hline$V 2$ & $\begin{array}{l}\text { Volume of flask used } \\
\text { for preparing diluted } \\
\text { sample* }\end{array}$ & $1000 \mathrm{~mL}$ & $0.5 / \sqrt{ } 3=0.289$ & $1000 \mathrm{~mL}$ & $0.5 / \sqrt{3}=0.289$ \\
\hline$V 3$ & $\begin{array}{l}\text { Volume of Pipette for } \\
\text { preparing extractant* }\end{array}$ & $1 \mathrm{~mL}$ & $0.01 / \sqrt{ } 3=0.0058$ & $1 \mathrm{~mL}$ & $0.01 / \sqrt{ } 3=0.0058$ \\
\hline
\end{tabular}

* The standard uncertainty in volume is assuming rectangular distribution for the temperature variation 


\section{Propagation of uncertainty \& Expanded Uncertainty}

The propagation of uncertainty from different sources identified in Table 13 are used to calculate combined $\left(\mathrm{U}_{\mathrm{c}}\right)$ and Expanded uncertainty $\left(\mathrm{U}_{\mathrm{E}}\right)$ for both the compounds of OPP, which is summarized in Table 14.

Table 14: Calculation of Combined Uncertainty $\left(U_{c}\right)$ and Expanded Uncertainty $\left(U_{E}\right)$

\begin{tabular}{|c|c|c|c|c|c|c|}
\hline & \multicolumn{3}{|c|}{ Parathion Methyl } & \multicolumn{3}{|c|}{ Malathion } \\
\hline & $f$ & $\mathrm{u}(f)$ & $(\mathrm{u}(f) / f)^{\wedge} 2$ & $f$ & $\mathrm{u}(f)$ & $(\mathrm{u}(f) / f)^{\wedge} 2$ \\
\hline Calibration & $\begin{array}{c}17.422 \mu \mathrm{g} / \\
\mathrm{mL}\end{array}$ & 2.93 & 0.0283 & $\begin{array}{l}15.397 \mu \mathrm{g} / \\
\mathrm{mL}\end{array}$ & 3.799 & 0.0609 \\
\hline Repeatability & $\begin{array}{l}17.422 \mu \mathrm{g} / \\
\mathrm{mL}\end{array}$ & 0.0441 & 0.0000 & $\begin{array}{l}15.397 \mu \mathrm{g} / \\
\mathrm{mL}\end{array}$ & 0.044 & 0.0000 \\
\hline Recovery & $10 \mu \mathrm{g} / \mathrm{mL}$ & 0.88 & 0.0077 & $10 \mu \mathrm{g} / \mathrm{mL}$ & 0.88 & 0.0077 \\
\hline Volume (1 mL) & $1 \mathrm{~mL}$ & 0.0058 & 0.0000 & $1 \mathrm{~mL}$ & 0.006 & 0.0000 \\
\hline Volume (1000 mL) & $1000 \mathrm{~mL}$ & 0.289 & 0.0000 & $1000 \mathrm{~mL}$ & 0.289 & 0.0000 \\
\hline Volume (1 mL) & $1 \mathrm{~mL}$ & 0.0058 & 0.0000 & $1 \mathrm{~mL}$ & 0.006 & 0.0000 \\
\hline$\sum\left(\mathrm{U}_{\mathrm{f}} / \mathrm{f}\right)^{2}$ & & & 0.0361 & & & 0.0687 \\
\hline $\begin{array}{l}\text { Propagation of Ur } \\
\sqrt{ } \sum\left(\mathrm{U}_{\mathrm{f}} / \mathrm{f}\right)^{2}\end{array}$ & rtainty (U & $/$ c) $=$ & 0.1900 & & & 0.2621 \\
\hline Concentration of dil & ed wastewate & (C) & $17.42 \mu \mathrm{g} / \mathrm{L}$ & & & $15.4 \mu \mathrm{g} / \mathrm{L}$ \\
\hline Combined Uncertain & & & $3.31 \mu \mathrm{g} / \mathrm{L}$ & & & $4.04 \mu \mathrm{g} / \mathrm{L}$ \\
\hline Expanded Uncertain & , $\mathrm{U}_{\mathrm{E}},(\mathrm{K}=2 \mathrm{a}$ & $95 \% \mathrm{CI})$ & $6.62 \mu \mathrm{g} / \mathrm{L}$ & & & $8.08 \mu \mathrm{g} / \mathrm{L}$ \\
\hline
\end{tabular}

From Table 14, it is apparent that the major contribution to uncertainty comes from the standard calibration and recovery of the analyte in replicate analysis inherent to GCMS instrumentation. Finally, the concentration of Parathion Methyl in diluted PT sample was found to be $17.4 \pm 6.6 \mu \mathrm{g} / \mathrm{L}$ and that of Malathion was $15.4 \pm 8.1 \mu \mathrm{g} / \mathrm{L}$.

\section{Comparison of Lab and PT Reports}

The calculated test results of two OPP compounds and the measurement uncertainty are compared with the PT reports in Figure 4. It is observed that the results submitted by this laboratory are slightly positively biased from the assigned value of the PT provider. The relative uncertainties of Parathion Methyl and Malathion from this laboratory are $\mathbf{3 8 \%}$ and $\mathbf{5 2 . 5} \%$ respectively. This is relatively lower than the PT interlaboratory variation of $60 \%$ for each component. 

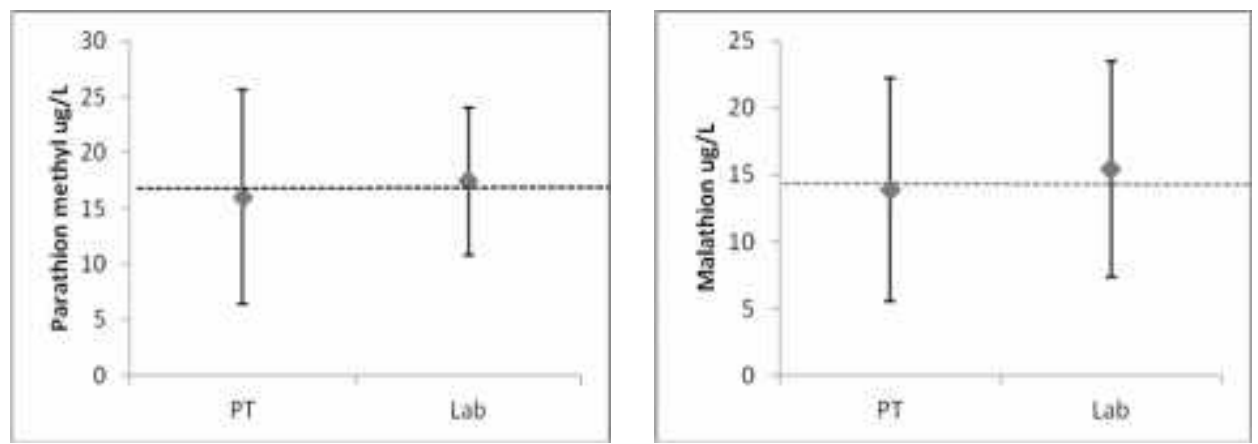

Fig. 4. Comparison of Proficiency Testing (PT) report and Lab report with measurement uncertainty for two OPP compounds

\section{CONCLUSION}

Analytical measurement is a constant need of a modern society as a public health advisory for assuring required quality specifications of consumers' products such as food, drinks and pharmaceuticals. In certifying materials for specific use/consumption, analytical testing laboratories all over the world report test results with assigning a level of uncertainty without which the results are not considered as scientific facts. In the context of Bangladesh, however, most of the testing laboratories report analytical results without quoting uncertainties associated with the results. Such test results either in scientific research or in international trade and commerce are not of any significance and as such are not any more acceptable.

To overcome this limitation in our efforts in materials testing for quality specifications, the modern concepts of quantifying uncertainties in measurements are introduced and how these concepts are used to quantify measurement uncertainties in chemical and biochemical analyses is illustrated with field sample analysis using instrumental methods such as atomic absorption spectroscopy and GC-MS spectrometry. This communication would thus enable testing laboratories operating in Bangladesh to report their analytical test results with a reliable statement on the level of uncertainties associated with the test results.

\section{REFERENCES}

Brynn, D. Hibbert. 2007. Quality Assurance for the Analytical Chemistry Laboratory, Oxford University Press, p. 161.

DOI: 10.1039/AN9952002303. 1995. Analyst, 120: 2303-2308.

EURACHEM/CITAC Guide CG 4: Quantifying Uncertainty in Analytical Measurement, Third Edition, S. L. R. Ellison and A. Williams (Editors). 2012. QUAM: 2012.P1, 2012.

GUM: "Guide to the Expression of Uncertainty in Measurement" (JCGM 100:2008), first published in 1993 by ISO in collaboration with BIPM, IEC, IFCC, ILAC, IUPAC, IUPAP and OIML; www.bipm.org. 
Harris, C. Daniel 2010. Quantitative Chemical Analysis, Eighth Edition International, 2010.

Harvey, David. 2000. Modern Analytical Chemistry, DePauw University, McGraw Hill, Chapter $15, \mathrm{p} 995$.

International Standard, ISO/IEC 17025 : 2005(E). General Requirements for the Competence of Testing and Calibration Laboratories, Second Edition. 2005. (Clause 5.4.6, p 14); Estimation of Uncertainty of Measurement.

Kateman, G. and L. Buydens. 1993. Quality Control in Analytical Chemistry, (Second Edition, Chemical Analysis Series), p 155.

Miller, J.C. and J.N. Miller. 1993. Statistics for Analytical Chemistry, $3^{\text {rd }}$ Edition, Ellis Harwood Limited.

(Received revised manuscript on 31 December, 2017) 